\title{
Explaining output growth and total factor productivity changes using production frontier: The case of Ethiopian smallholder's farming
}

\author{
Oumer Berisso Metaksa \\ Department Technology and Innovation Management, School of Humanities and Social Sciences, Adama Science and \\ Technology University, Adama, Ethiopia.
}

Received 27 February, 2020; Accepted 19 June, 2020

\begin{abstract}
This paper provides a parametric decomposition of output growth and total factor productivity changes, extending production approach to the case of non-neutral stochastic frontier. The results were based on unbalanced panel data from Ethiopian smallholder farmers observed over the period 1999-2015. The study decomposes output growth into input growth and total factor productivity changes while both were further decomposed into components. Output growth was decomposed into individual inputs contribution, whilst total factor productivity change decomposed into technical change, scale effect and technical efficiency changes. The empirical findings indicate output growth was mainly driven by total factor productivity changes $(71 \%)$ while $22 \%$ attributed to input growth. Technical change found to be the main source of total factor productivity while scale effect also contributed significantly. Technical efficiency change was found to be the main source for the reduction of total factor productivity and so in output growth. The result indicates both changes due to inputs use and farm-characteristics were found the most important, in explaining technical efficiency changes, cancelling the negative impact due to autonomous changes and environmental factors. The finding implies there are total factor productivity changes and the output growth in cereal farming is mainly driven by technical change, suggesting policies aim at enhancing technology adoption and investment in modernizing agriculture are significantly effective. Thus policies directed toward enhancing agricultural technologies that improve technical change, enable farmers to benefit from scale of operations and their best practice form essential part of the overall agricultural policies.
\end{abstract}

Key words: Output growth, total factor productivity, decomposition, stochastic frontier, farming, Ethiopia.

\section{INTRODUCTION}

As accumulating factor of production and productivity growth, appears among the major determinants of economic growth; enhancement in production efficiency and total factor productivity (TFP) are probably the key

E-mail: ub_ansha@yahoo.com; obansha15@gmail.com; oumer.beriso@astu.edu.et. Tel: +251911 655511.

JEL classification: D13, D24, Q1, Q10, Q12, Q54, O33. 
elements that can ensure a continuous economic growth with a relatively low cost. Particularly in agrarian society, production performance study is an important indicator for the analysis of the overall economic growth, provides society with an opportunity to increase people's welfare and global competitiveness. Production performance analysis is an important field of research with possible implication in the discussions on food security and poverty alleviation, especially in the developing world. Besides a high rate of factor productivity growth in the agricultural sector is a necessary presupposition for a self-sufficient economy, at least in insuring own food security. Moreover, the raising of unemployment in a country in combination with the increase of population requires, necessarily, a growth in agricultural production and its productivity. It is, therefore, worthwhile to ask: What determinants should policymaking focus on to enhance productive efficiency and TFP growth. Analyzing farm production performance, identifying the sources of TFP growth and inefficiencies is an important step forward to assess the developmental role of agriculture in developing agrarian economies, like Ethiopia.

Agricultural sector plays an important role in overall economic growth in Ethiopia (World Bank, 2017), and it has significant spillover effects on the other sectors of the nation as well. Agriculture accounts for $38.5 \%$ of the country's gross domestic product (GDP), up to $81 \%$ of total export earnings and provides livelihood to more than $83 \%$ of the population (African Development Bank [AfDB], 2018). Despite frequent droughts and traditional farming practices in the country, Ethiopia has huge agricultural potential due to its ample arable land, an abundant workforce and diverse Agro-Ecological Zones (Beyan et al., 2013). The country's agriculture is known by low productivity, caused by an adverse combination of demographic, institutional constraints including environmental factors. In the country's crop production, mainly by the smallholder farmers, who provide the major share of the agricultural output; commonly employ backward production technology and limited modern inputs. Ethiopia's grain crop production is mainly dominated by cereal farming which is the most vital crop in the country; as the major food crop; comprise about two-third of the agricultural share of GDP and one-third of the national GDP. Ethiopia's agricultural sector is characterized by inefficiencies and heterogeneous increase in TFP growth in which cereals have shown a steady low productivity growth rate in recent decades; is one of the main challenges facing the country (AfDB, 2018). These underline the importance of assessing farm performance; with a potential policy implication is an important issue for such an agrarian country with a food deficit gap and limited capacity for adopting new technologies, is not a matter of choice but is instead a must.

Several studies have been done on farm performance in Ethiopian agriculture; however, few of these studies have linked productive efficiency to TFP growth decomposition. More importantly most studies have paid relatively little attention to connect efficiency analysis to output/TFP growth and its determinants while explaining TFP growth analysis in Ethiopian agriculture including the cereal subsector (Yohannes, 2016; Gebreegziabher et al., 2013). Moreover, most studies on crop productivity and efficiency in the country are outdated and have ignored unobserved heterogeneity and weather factor effects in productivity and efficiency analysis. Beside, results from previous performance studies have shown that methodological approaches (estimation techniques) and other study-specific characteristics (functional form, sample size, dimensionality, and geographical region) could affect the empirical estimates of productivity growth and efficiency analysis. In assessment of the farm performance, approach to use, which is the mainstay methodology of analysis, it is not distinguished to focus on the analysis of TFP or on the analysis of technical efficiency, but could be both. For instance, the conventional index number approach to the analysis of TFP cannot distinguish between a shift of production function (technical progress) and a movement along a production function (technical efficiency). In contrast the econometric approach is a flexible technique not only for identifying the sources of output growth and TFP changes but also for considering the technical efficiency of farms by explicitly specifying the underlying production structure. Therefore, it requires assessing level of productive efficiency and TFP growth as well as knowing root cause of their differentials in Ethiopian cereal farming. Along these lines, this paper provides a parametric decomposition of output growth and TFP change, extending the production approach to the case of non-neutral stochastic frontier that incorporates technical inefficiency. The empirical results were based on unbalanced panel data of Ethiopian smallholder cereal farmers observed during the 1999-2015 cropping period.

The paper used a Stochastic Frontier Analysis (SFA) applying recently developed- a four-component error panel data stochastic production frontier (SPF) model due to Kumbhakar et al. (2014), distinguished between farm-heterogeneity, persistent and transient inefficiencies and random error components. The model has an advantage over the traditional approaches by separating time-invariant heterogeneity from inefficiency. Accordingly, after estimating technical efficiency components, we decomposed output growth and TFP changes following Kumbhakar (2000) and other related growth decomposition approaches. In particular we utilized Karagiannis and Tzouvelekas (2005) who extended the earlier methods and adapted to the parametric approach for the decomposition of output growth and TFP changes to the case of non-neutral SPF. Consequently, output growth is decomposed into input growth (size effect) and TFP growth, and each was further decomposed into several components. The output 
growth is decomposed into individual inputs contribution while TFP growth was decomposed into the technical change (TC), scale effect (SE) and technical efficiency changes (TECs). Within the proposed formulation, however, the TEC effect itself is attributed not only to autonomous changes (passage of time) but also attributed to change due to inputs use, change due to farm specific-characteristics and change due to environmental factors. Thus, the TECs in turn are decomposed into four components: (a) change in passage of time, (b) change in inputs use, (c) change in the farm-specific characteristics and (d) change in environmental factors.

The study contributes to the existing literature and provides valuable information on the country's farming performance. Apart from analytical reasons, having farmheterogeneity disentangled estimates and information about persistent and transient components of inefficiency is important; as each component provides different information with different policy options. Furthermore, appropriately quantifying the sources of output growth and TFP changes is also important for analyzing a sector's long-term prospects and policy-related issues. The greater the portion of output growth attributed to TFP is, the better the long-term prospects for farm production are, as the size effect (input growth) is considered a costly source of growth; whereas TFP is costless, at least from farmers' point of view. In addition, the relative importance of each TFP component is by itself informative as the factors (and seemingly the policies) affecting the various sources of TFP growth are not necessarily the same. For example, as stated in Karagiannis and Tzouvelekas (2005); R\&D has a considerable impact on the TC effect but it rarely affects TECs. In contrast, for instance, agricultural extension service may have an effect both through its impact on the rate of diffusion and by improving farmers' managerial and organizational ability. Hence, if the driving forces of growth are to be taken into account in shaping development policies, then decomposition analysis could provide some useful insights. To the best of our knowledge, this is the first paper that examines output growth as well as decomposes TFP growth into TC, SE, and TEC with further decomposition of TECs in turn into four components, for Ethiopian cereal farming.

\section{MATERIALS AND METHODS}

Brief overview of stochastic production frontier model with four-error components

The method used in this paper is basically drawn from Kumbhakar et al. (2014) and Karagiannis and Tzouvelekas (2001, 2005). The recently introduced penal data SPF models (Kumbhakar et al., 2014) are extended to include four-component error terms in which technical efficiency and technological progress vary over time and across production units. Consider that, there are sample data on $\mathrm{N}$ farmers operating in time period t that utilize various inputs to produce a non-negative farm output through a technology described by a well-behaved production frontier. The specification of panel data versions of the 1990s SPF model can be generally written as:

$$
Y_{i t}=f\left(X_{i t}, t ; \beta\right) * \exp \left(\varphi_{i t}\right)=f\left(X_{i t}, t ; \beta\right) * \exp \left(\varepsilon_{i t}-\tau_{i t}\right)
$$

where $i=1, \ldots, N$ denotes observations - is an index for $i^{\text {th }}$ farmer and $t=1, \ldots, T$ denotes time period $t . Y_{\text {it }}$ is output produced by farmer $i$ at time period t while $X_{i t}$ is a $(1 \times k)$ vector of input variables of the $\mathrm{i}^{\text {th }}$ farmer at time period t. $f\left(x_{i t}, t ; \beta\right)$, the SPF, where $t$ is a time index that serves as a proxy for TC and $\beta$ is a $(k \times 1)$ vector of unknown parameters to be estimated. The term: $\varphi_{i t}$, is a "stochastic composed error term; where, the $\mathrm{T}_{i t} \geq 0$ is technical inefficiency term of individual $i$; and $\varepsilon_{i t}$ is a symmetric random error that accounts for statistical noise term. However, a number of SPF models in panel data have been developed successively giving rise to alternative measures of technical inefficiency. Kumbhakar and Heshmati (1995) interpreted $\tau_{i t} \geq 0$ as time-varying technical inefficiency and added an extra component $\eta_{i} \geq 0$ to represent persistent inefficiency. The persistent component is consistent with the models used in the 1980s (Schmidt and Sickles, 1984), whereas the timevarying component is consistent with the models developed in the 1990s (Battese and Coelli, 1992). On the other hand, recently a philosophical question about the way of interpreting $\eta_{i}$ has been raised -- should one view it as persistent inefficiency as in Kumbhakar and Heshmati (1995) or as firm-heterogeneity that captures the effects of (unobserved) time-invariant covariates that have nothing to do with inefficiencies as in Greene (2005a, 2005b). More recently Kumbhakar et al. (2014) and others introduced the first panel data SPF model including the arguments (heterogeneity and persistent inefficiency) by splitting the error term into fourcomponents persistent inefficiency, transient inefficiency, random farm-heterogeneity and the random noise; thus decomposed the error term in equation (1) as: $\tau_{i t}=\eta_{i}+u_{i t}$ and $\varepsilon_{i t}=\mu_{i}+v_{i t}$ to obtain a model:

$$
Y_{i t}=f\left(X_{i t}, t ; \beta\right) * \exp \left(\varphi_{i t}\right)=f\left(X_{i t}, t ; \beta\right) * \exp \left(\mu_{i}+v_{i t}-\eta_{i}-u_{i t}\right)
$$

The model in (2) can be written as: $y_{i t}=\alpha_{0}+x_{i t}^{\prime} \beta+\mu_{i}+v_{i t}-\eta_{i}-u_{i t}$ after taking logarithms of both sides; where, $y_{i t}$ is logarithm of the output variable, $x_{i t}$ is logarithms of the input variables. The parameter $\alpha_{0}$ is a common intercept; $\boldsymbol{\mu}_{\boldsymbol{i}}$ is a farm-specific effect that captures time-invariant farms' heterogeneity (e.g. soil quality), which has to be disentangled from persistent individual effects (e.g. skill of the farmer). The term $v_{i t}$ is the random noise term, while the nonnegative terms $\boldsymbol{\eta}_{\boldsymbol{i}}$ and $\boldsymbol{u}_{i t}$ capture persistent inefficiency and transient inefficiency effects, respectively.

The SPF model in (2) due to Kumbhakar et al. (2014) refers to as the Generalized True Random Effects (GTRE) model because it is a generalization of the true random effect model. A model can be estimated assuming that either the inefficiency component $\left(u_{i t}\right)$ is a fixed parameter that directly influences the dependent variable (the fixed-effects model) or assuming that the inefficiency component $\left(u_{i t}\right)$ is a random variable that has a correlation with the independent variables (the random-effects model).

Theoretical framework: Decomposing output growth and TFP changes

To decompose output growth and TFP changes, following 
Kumbhakar (2000), based on the specification of Kumbhakar et al. (2014) and the methods of Alexander et al. (2015) and Karagiannis and Tzouvelekas (2005), we adopted the parametric approach to the case of non-neutral SPF. Consider a panel data production function of single production output, with the deterministic production frontier part of (2). Since farmers are not necessarily technically efficient, $Y_{i t} \leq \mathrm{f}\left(X_{i t} ; t\right)$. Hence, based on Farrell's, 1957 the output-oriented measure of technical efficiency of a producer at a certain point in time can be expressed as the ratio of actual output to the maximum potential output; given as $T E_{i t}\left(X_{i t} ; t\right)=Y_{i t} / f\left(X_{i t} ; t\right)$, where $0<T E_{i t}\left(X_{i t} ; t\right) \leq 1$. Now in order to compute the output growth, we rewrite the above productive efficiency expression as in Equation 3:

$Y_{i t}=f\left(X_{i t}, t ; \beta\right) T E_{i t}\left(X_{i t}, t\right)$

By omitting the "it" subscripts for simplicity, taking logarithm of both sides of Equation 3 and totally differentiating with respect to time, we obtain:

$$
\frac{d \ln T E}{d t}=\frac{d \ln Y}{d t}-\sum_{i=1}^{k} \frac{\partial \ln f(X, t ; \beta)}{\partial X_{i}} \frac{d X_{j}}{d t}-\frac{\partial \ln f(X, t ; \beta)}{\partial t}
$$

which can be rewritten as

$$
\frac{d \ln Y}{d t}=\frac{\partial \ln f(X, t ; \beta)}{\partial t}+\sum_{j=1}^{k}\left\{\frac{\partial \ln f(X, t ; \beta)}{\partial X_{j}} \frac{1}{X_{j}} \frac{d X_{j}}{d t}+\frac{d \ln T E}{d t}\right\}
$$

Now let $\mathrm{y}=\ln Y$ and similarly $\mathrm{x}=\ln X$ and denoting the growth rate of a variable $Z$, by $\dot{z}$ - that is, $\dot{z}=\partial \ln Z / \partial t$; equivalently we have:

$$
\begin{aligned}
\dot{y} & =\frac{\partial \ln f(x ; t)}{\partial t}+\sum_{j=1}^{J} \frac{\partial \ln f(x ; t)}{\partial \ln x_{j}} \dot{x}_{j}+\frac{\partial T E(x ; t)}{\partial t} \\
& =\dot{T}(x ; t)+\sum_{j=1}^{J} \frac{\partial \ln f(x ; t)}{\partial \ln x_{j}} \dot{x}_{j}+\dot{T} E(x ; t)=T C+\sum_{j=1}^{J} \varepsilon_{j}(x ; t) \dot{x}_{j}+T E C
\end{aligned}
$$

where, $\dot{T}(x ; t)=\partial \ln f(x ; t) / \partial t$ is the technical change (TC), $\dot{T} E(x ; t)=\partial T E(x ; t) / \partial t=\partial u / \partial t$ is the technical efficiency change (TEC), and $\varepsilon_{j}(x ; t)=\partial \ln f(x ; t) / \partial \ln x_{j}$ is the output elasticity of the $\mathrm{j}^{\text {th }}$ input. Now we include a vector of farm-specific characteristics and vector of environmental factors in the above formulation to extend our model to correspond the Huang and Liu (1994) model. For this let $z=\left(z_{1}, \ldots, z_{m}\right) \& w=\left(w_{1}, \ldots, w_{k}\right)$ are the inefficiency effects vectors; includes a vector of farm-specific characteristics and vector of environmental factors, respectively. Hence following Karagiannis and Tzouvelekas (2005), (3) above can be rewritten as:

$Y=f(X, t ; \beta) T E(X, z, w ; t)$

So by making necessary rearrangement and substitutions; and taking logarithm of both sides of (4) and differentiating with respect to time, we obtain an extended form of decomposed output growth which has a form of:

$$
\begin{aligned}
\dot{y} & =\dot{T}(x ; t)+\sum_{j=1}^{J} \frac{\partial \ln f(x ; t)}{\partial \ln x_{j}} \dot{x}_{j}+\dot{T} E(x, z, w ; t)+\sum_{j=1}^{J} \frac{\partial T E(x, z, w ; t)}{\partial \ln x_{j}} \dot{x}_{j}+\sum_{m=1}^{M} \frac{\partial T E(x, z, w ; t)}{\partial \ln z_{m}} \dot{z}_{m}+\sum_{k=1}^{K} \frac{\partial T E(x, z, w ; t)}{\partial \ln w_{k}} \dot{w}_{k} \\
& =T C+\sum_{j=1}^{J} \varepsilon_{j}(x ; t) \dot{x}_{j}+T E C+\sum_{j=1}^{J} \frac{\partial T E(x, z, w ; t)}{\partial \ln x_{j}} \dot{x}_{j}+\sum_{m=1}^{M} \frac{\partial T E(x, z, w ; t)}{\partial \ln z_{m}} \dot{z}_{m}+\sum_{k=1}^{K} \frac{\partial T E(x, z, w ; t)}{\partial \ln w_{k}} \dot{w}_{k}
\end{aligned}
$$

Now following Kumbhakar (2000) to decompose TFP into components, we defined TFP growth as output growth unexplained by input growth; that is,

$$
\boldsymbol{T F} \boldsymbol{P}=\dot{y}-\sum_{j=1}^{J} S_{j} \dot{x}_{j}
$$

$$
\begin{aligned}
T \dot{F P} & =\frac{\partial \ln f(x, t)}{\partial t}+\sum_{j=1}^{J}\left\{\varepsilon_{j}(x, t)-\lambda_{j}\right\} \dot{x}_{j}+\frac{\partial T E(x, z, w ; t)}{\partial t} \\
& +\sum_{j=1}^{J} \frac{\partial T E(x, z, w ; t)}{\partial \ln x_{j}} \dot{x}_{j}+\sum_{m=1}^{M} \frac{\partial T E(x, z, w ; t)}{\partial \ln z_{m}} \dot{z}_{m}+\sum_{k=1}^{K} \frac{\partial T E(x, z, w ; t)}{\partial \ln w_{k}} \dot{w}_{k}
\end{aligned}
$$

This is a conventional Divisia index of productivity change defined as the difference between the rate of change in the output and the rate of change in the input quantity index. Substituting this index into Equation 5, that is replacing $\dot{y}$ in Equation 6 with Equation 4, the TFP growth in Equation 5 can be rewritten as:
Further by letting $R T S=\sum_{j=1}^{J} \varepsilon_{j}(x ; t)$ denotes the returns to scale (RTS) so that $\lambda_{j}=\varepsilon_{j} / R T S ;(7)$ may be rewritten as:

$$
\begin{aligned}
T \dot{F} P & =\frac{\partial \ln f(x, t)}{\partial t}+(R T S-1) \sum_{j=1}^{J}\left\{\frac{\varepsilon_{j}(x ; t)}{R T S}\right\} \dot{x}_{j}+\frac{\partial T E(x, z, w ; t)}{\partial t} \\
& +\sum_{j=1}^{J} \frac{\partial T E(x, z, w ; t)}{\partial \ln x_{j}} \dot{x}_{j}+\sum_{m=1}^{M} \frac{\partial T E(x, z, w ; t)}{\partial \ln z_{m}} \dot{z}_{m}+\sum_{k=1}^{K} \frac{\partial T E(x, z, w ; t)}{\partial \ln w_{k}} \dot{w}_{k}
\end{aligned}
$$


Equation 8 is the TFP change, in which TFP changes may be attributed to three sources: the TC effect; scale effect and TEC effect (the sum of the last four terms). Thus, in decomposing the TFP changes as in Equation 8: (i) The first term on the right-hand side (RHS) measures the TC effect that relates to the technological progress, including not only advances in physical technologies, but also innovation in the overall knowledge base that leads to better decision making and planning. The technological progress is positive (negative) under progressive (regressive) TC, respectively or vanishes when there is no TC. (ii) The second term on the RHS measures the SE that refers to the proportionate increase in output due to proportionate increase in all inputs in the production process. Note that the sign of SE depends on both the magnitude of the inputs elasticity and the changes of the aggregate input over time. It is positive (negative) under increasing (decreasing) RTS as long as input use increases and vice versa. This term vanishes when either the technology is characterized by constant RTS. (iii) The remaining terms (last four terms) on the RHS constitute the TEC measure, which contributes positively (negatively) to TFP growth as long as efficiency changes are associated with movements towards (away from) the production frontier. Thus, what really matters is not the degree of technical efficiency per time, but its changes overtime. That is, even at low levels of technical efficiency, output gains may be achieved by improving resource use. These TECs may be due to four factors: changes due to passage of time, due to input use, due to the farm-specific characteristics, and due to environmental factors; the third, fourth and last terms in the RHS of Equation 8 respectively.

These four terms are closely related to the form of the production frontier. If it is specified as non-neutral SPF, which is the most general formulation, all of these terms are relevant and should be taken into account. If instead a neutral SPF is assumed, the fourth term vanishes and then there are two alternatives. If technical efficiency is specified as a technical inefficiency effect model (Battese and Coelli, 1992), both the third and the fifth term should be considered, but if technical efficiency is modeled as a pure timevarying process, following the specifications of Kumbhakar (1990) only the third term should be taken into account. To extend the above non-neutral parametric approach decomposition of TFP changes, to similar decomposition of the output growth, we include the input growth to Equation 8. Thus the output growth decomposition format will be given by:

$$
\begin{aligned}
\dot{y} & =\frac{\partial \ln f(x ; t)}{\partial t}+(R T S-1) \sum_{j=1}^{J}\left\{\frac{\varepsilon_{j}(x ; t)}{R T S}\right\} \dot{x}_{j}+\frac{\partial T E(x, z, w ; t)}{\partial t}+\sum_{j=1}^{J} \frac{\partial T E(x, z, w ; t)}{\partial \ln x_{j}} \dot{x}_{j} \\
& +\sum_{m=1}^{M} \frac{\partial T E(x, z, w ; t)}{\partial \ln z_{m}} \dot{z}_{m}+\sum_{k=1}^{K} \frac{\partial T E(x, z, w ; t)}{\partial \ln w_{k}} \dot{w}_{k}+\sum_{j=1}^{J} \frac{\varepsilon_{j}(x ; t)}{R T S} \dot{x}_{j}
\end{aligned}
$$

Where; the last term in Equation 9 refers to the size effect that captures the contribution of aggregate input growth (factor accumulation) to output growth. Output increases (decreases) are associated with increases (decreases) in the aggregate input, ceteris paribus. Also, the more essential an input is in the production process, the higher its contribution is on the size effect. Thus, within Equation 9, however, TECs are attributed not only to change components presented in Equation 8 but also to changes in input use. A very different relationship has been used in previous studies to decompose output growth, simply by focusing on rate change of output under constant RTS; namely:

$$
\dot{y}=\dot{T} E(z, w, x, t)+\dot{T}(x ; t)+\sum_{j=1}^{J} \varepsilon_{j}(x ; t) \dot{x}_{j}=T C+\sum_{j=1}^{J} \varepsilon_{j} \dot{x}_{j}+T E C
$$

This approach is a step back from the TFP changes, but it might be easier to explain and is, perhaps, more intuitive; due to its restrictive version of Equation 9 in the sense that it implicitly assumes (i) a neutral SPF, (ii) a pure time-varying specification for the technical inefficiency model, and (iii) a constant RTS technology. Thus, Equation 9 and 10 would yield very different results concerning the sources of output growth. Specifically, the relative contribution of TFP to output growth is overestimated (underestimated) when Equation 10 is employed and decreasing (increasing) RTS prevail; whereas the opposite is true for the size effect. Based on Equation 9, RTS and the rate of TC can be calculated as:

$$
R T S_{i t}=E_{j i t}=\sum_{j=1}^{J} \varepsilon_{j i t}=\sum_{j=1}^{J}\left(\beta_{j}+\sum_{k=1}^{J} \beta_{j k} X_{k i t}+\beta_{j t} T\right)
$$

where ${ }^{\mathcal{E}_{\mathrm{jit}}}$ are input elasticities

$$
T C_{i t}=\dot{T}_{i t}(x ; t)=\frac{\partial \ln y_{i t}}{\partial \ln T}=\beta_{t}+\beta_{t t} T+\sum_{j=1}^{J} \beta_{j t} \ln X_{j i t}
$$

Note that, the TC in Equation 11 consists of two parts; the pure/neutral TC: $\left(\beta_{t}+\beta_{t t} T\right)$ and the non-neutral TC: $\left(\Sigma \beta_{j t} \ln X_{j i t}\right)$ parts. Pure TC refers to neutral shift of the production function due to time alone, non-neutral TC means input-biased TC

Lastly, following Wang and Schmidt (2002) the components of the TECs - Change due to passage of time $\left(T E C_{T}\right)$, changes due to farm-characteristics $\left(T E C_{Z}\right)$, changes due to environmental factors $\left(T_{E C}\right)$ and changes due to inputs $\left(T E C_{X}\right)$ are computed respectively as:

$$
\mathrm{TEC}_{\mathrm{T}_{i t}}=\delta_{t}+\delta_{t t} T ; \quad \mathrm{TEC}_{\mathrm{Z}_{\text {it }}}=\sum_{m=1}^{M} \delta_{m} \dot{z}_{m} ; \quad \mathrm{TEC}_{\mathrm{W}_{, i t}}=\sum_{k=1}^{K} \delta_{k} \dot{\mathrm{w}}_{k} \text { and } \mathrm{TEC}_{\mathrm{X}_{\text {it }}}=\sum_{j=1}^{J} \delta_{j} \dot{x}_{j}
$$

The above relationships, Equations 9 to 12 are used to implement the decomposition of TFP changes and output growth.

\section{The empirical model and estimation approach}

For the estimation purpose, given the SPF in model (1), we approximate the underlying technology $f\left(x_{i t} ; \beta\right)$ using a translog (TL) functional form; a technology that commonly has been preferred as a more flexible form that allows for interaction of inputs. Thus; we estimate a SPF panel data model using specification: 
$\ln Y_{i t}=\beta_{0}+\sum_{j=1}^{J} \beta_{j} \ln X_{j i t}+\beta_{t} T_{t}+\frac{1}{2}\left(\sum_{j=1}^{J} \sum_{h=1}^{H} \beta_{j h} \ln X_{j i t} \ln X_{h i t}+\beta_{t t} T_{t}^{2}\right)+\sum_{j=1}^{J} \beta_{j t} \ln X_{j i t} T_{t}+\varphi_{i t}$

where: $\ln Y_{i t}$ is the logarithm of output of farmer $i$, in time period $t$. $\ln X_{i t}$ is a vector of logarithm of inputs. $\mathrm{T}$ is a time trend and $\beta_{\mathrm{s}}$ are unknown parameters to be estimated. $\varphi_{i t}$, is a stochastic composite error term; that can be decomposed as: $\varphi_{i t}=\varepsilon_{i t}-\tau_{i t}=\left(\mu_{i}+v_{i t}\right)-\left(\eta_{i}+u_{i t}\right)$.

To specify the determinants of transient inefficiencies we make the variance parameters of $\boldsymbol{u}_{i t}$ function of the determinants. In modeling $\boldsymbol{u}_{i t}$, it is assumed that the mean of the pre-truncated distribution depends on both input use and farm-specific characteristics assuming a homoscedastic distribution for the variance parameter. For this, following Karagiannis and Tzouvelekas (2005), we implemented inefficiency effect model that corresponds to a non-neutral SPF model (Huang and Liu, 1994). Thus the inefficiency term $\boldsymbol{u}_{i t}$ as explained in Equation 1 is given as:

$u_{i t}=\delta_{0}+\sum_{m=1}^{M} \delta_{m} Z_{m i t}+\sum_{k=1}^{K} \delta_{k} E_{k i t}+\delta_{t} T+\sum_{j=1}^{J} \delta_{j} X_{j i t}+w_{i t}$

Where: $u_{i t}$ refer to farmer's transient inefficiency indices as estimated by SPF model; Z, E and X represent vectors of independent variables assumed to influence transient inefficiency. The variable $Z_{i t}$ denotes a vector of (farmer as well as farm-specific characteristics); $E_{i t}$ is a vector of environmental factors; $X_{i t}$ denotes the vector of production inputs. The terms $\delta$ 's are the inefficiency parameters to be estimated, and $w_{\text {it }}$ is the corresponding statistical noise.

After substituting Equation 13 and (14) into Equation 1) the resulting model is estimated using fixed-effect model which allows addressing the influences of omitted variables and provides consistent estimators (Baltagi, 2008). For estimation purpose we used multi-stage maximum likelihood estimation (MLE) method (Kumbhakar et al., 2015) to obtain estimate of efficiency components and compute marginal effects of the determinants of each type of inefficiency. Hence, in the one-stage approach, all parameters - frontier production in Equation 13 and inefficiency effects in Equation 14 are estimated simultaneously. It uses three steps to estimate the model, initially by rewriting the model in

Equation $2 y_{i t}=\alpha_{0}+x_{i t}^{\prime} \beta+\mu_{i}+v_{i t}-\eta_{i}-u_{i t} \quad$ as follows:

$$
y=\alpha_{0}^{*}+f\left(x_{i t} ; \beta\right)+\alpha_{i}+\varepsilon_{i t}^{*}
$$

where

$\alpha_{0}^{*}=\alpha_{0}-E\left(\eta_{i}\right)-E\left(u_{i t}\right) ;$ and $\alpha_{i}=\mu_{i}-\eta_{i}+E\left(\eta_{i}\right) ;$ and $\varepsilon_{i t}^{*}=v_{i t}-u_{i t}+E\left(u_{i t}\right)$ while $\alpha_{i}$ and $\varepsilon_{\text {it }}^{*}$ have zero mean and constant variance. Here, the newly rewritten model can be estimated in three steps as follows: The first step includes a standard random effect panel regression to estimate $\beta$ and predict the values of $\alpha_{i}$ and $\varepsilon_{i t .}^{*}$ In the second step, the time-varying technical efficiency is estimated using the predicted value of $\varepsilon_{\text {it }}^{*}$ from previous step by assuming $v_{i t} \sim N\left(0, \sigma_{v}{ }^{2}\right)$ and $u_{i t} \sim N^{+}\left(0, \sigma_{u}{ }^{2}\right)$. This procedure predicts the residual (transient) technical inefficiency index following Jondrow et al. (1982) or residual technical efficiency (RTE) index and marginal effects (MEs) using Battese and Coelli (1988): $R T E_{i t}=\exp \left(-u_{i t} \mid \varepsilon_{i t}^{*}\right)$.

In Step 3, following a similar procedure as in Step 2, $\eta_{i}$ is used to obtain the persistent technical efficiency (PTE) estimates and the corresponding inefficiency effects parameters simultaneously. For this, the best linear predictor of $\alpha_{i}=\mu_{i}-\eta_{i}+E\left(\eta_{i}\right)$ is estimated by assuming $\mu_{i} \sim N\left(0, \sigma_{\mu}^{2}\right)$ and $\eta_{i} \sim N^{+}\left(0, \sigma_{\eta}{ }^{2}\right)$ and applying standard half-normal SFM in a cross-sectional setting. The persistent technical inefficiency $\left(\eta_{\mathrm{i}}\right)$ is obtained through Jondrow's estimator and PTE index and MEs can be estimated using the $\mathrm{BC}$ formula: $P T E=\exp \left(-\hat{\eta}_{i}\right)$. Finally the overall technical efficiency (OTE) is then obtained from the product of persistent and residual efficiencies, that is, $O T E_{i t}=P T E_{i} \times R T E_{i t}$.

\section{DATA AND THE STUDY VARIABLES}

\section{The data and description of variables of the study}

This study employed panel data from the Ethiopian Rural Household Survey (ERHS) data of 4-rounds in years 1999, 2004, 2009 and 2015 collected from local Farmers Associations (FAs). The ERHS data were collected from randomly selected farm households in rural Ethiopia. It includes farm production and economic data collected from local FAs that were selected to represent the country's diverse farming systems. Moreover, important weather data; monthly average observations of rainfall and maximum and minimum temperature were obtained from Ethiopian Meteorology Authority from years 19942015 collected in stations close to the study villages.

\section{Study variables}

The output variable contains the value of cereal outputs, which combines aggregate cereal crops output measured in Ethiopian Birr (ETB) used as dependent variable for the frontier function. The input variables include conventional agricultural inputs: farm labor employed measured in Man-Day Units (MDUs); cereal sown farmland in hectares; amount of fertilizers used in kilograms; agricultural machinery implements in ETB; livestock ownership in Tropical Livestock Units (TLUs) as a proxy for wealth and livestock asset endowments; agrochemicals in ETB including pesticides, herbicides and insecticides; and oxen as animal draft power in number of the oxen owned as these are used during land preparation and harvesting periods; as the country's farming is mainly traditional. All monetarily measured variables were transformed to fixed ETB prices. In addition, we also included sets of inefficiency explaining 
Table 1. Summary statistics of continuous variables.

\begin{tabular}{lcccclcccc}
\hline $\begin{array}{l}\text { Frontier } \\
\text { variables }\end{array}$ & Mean & SD & Min. & Max. & $\begin{array}{l}\text { Inefficiency } \\
\text { variables }\end{array}$ & Mean & SD & Min. & Max. \\
\hline Output & 1.952 & 2.682 & 34.0 & 51.100 & Aver. Rainfall (AMP) & 82.1 & 26.9 & 47.5 & 145.9 \\
Fertilizers & 116.1 & 138.9 & 0.1 & 1.400 & Aver. Temp. (AMT) & 18.5 & 3.5 & 13.2 & 23.9 \\
Agrochemicals & 133.9 & 447.2 & 0.01 & 8.560 & Rainfall Variation & 0.02 & 0.01 & 0.01 & 0.03 \\
Labor & 342.6 & 714.2 & 3.0 & 8.333 .9 & Temp. Variation & 6.1 & 3.03 & 1.9 & 14. \\
Machinery & 336.7 & 1.776 & 0.5 & 36.540 & Household's size & 5.8 & 2.7 & 1.0 & 18.0 \\
Livestock & 6.5 & 5.9 & 0.01 & 58.8 & Number of plots & 3.6 & 2.5 & 1.0 & 16.0 \\
Oxen & 1.8 & 1.3 & 0.01 & 9.0 & Head's age & 51.2 & 15.4 & 18.0 & 103.0 \\
Farm-area & 1.7 & 1.2 & 0.02 & 11.0 & & & & & \\
\hline
\end{tabular}

Source: Author's calculations.

Table 2. Summary statistics for inefficiency effect dummy ( $1=$ yes) variables.

\begin{tabular}{lclclc}
\hline Variable & Percentage & Variable & Percentage & Variable & Percentage \\
\hline Credit-access & 52.25 & Tertiary-schooling & 1.03 & Remittance & 18.51 \\
Head's-gender (female) & 23.42 & Soil-conservation & 39.87 & Irrigation & 19.42 \\
Primary-schooling & 40.17 & Water-harvesting & 26.58 & Off/non-farm & 31.25 \\
Secondary-schooling. & 7.90 & Agricultural-extension & 38.29 & If any ox & 80.64 \\
\hline
\end{tabular}

Source: Author's calculations.

variables. Based on the existing literature source of technical inefficiency includes farmer-specific characteristics (e.g., education, age, gender, and farming experience); household physical endowments (e.g., farmsize and family-size); and access to agricultural extension and credit use, adoption technologies and environmental (weather/ecological) factors. Besides the time trend variable is also included both in the production as well as the inefficiency functions. The time trend variable in the production function represents the rate of TC; while the time trend in the inefficiency function represents changes in technical inefficiency over time.

The weather dataset contains Annual Mean Precipitation (AMP) measured in millimeters $(\mathrm{mm})$ and Annual Maximum Temperature (AMT) in degree Celsius $\left({ }^{\circ} \mathrm{C}\right)$ and their variability (measured by their coefficients of variation). AMT is based on two indicators: Monthly Mean Temperature (MMT) and the Diurnal Temperature Range (DTR). MMT is calculated as the median between the observed monthly maximum and minimum temperatures, whereas DTR is the difference between the monthly temperatures. Finally, AMT is calculated by adding half of DTR to MMT (Harris et al., 2014) and is used as a measure of extreme temperature because it captures temperatures at a time when evaporation is higher. In addition to the mean of the weather variables, following Barnwal and Kotani (2013), we used coefficient of variation, which is a measure of monthly deviation within a year to capture variability. Annual climatic data for the weather variables in the study were calculated as the 12month average (Harris et al., 2014). The summary statistics of the data is provided in Tables 1 and 2. Table 1 shows that the sampled farmers produced an average of 19.52quintals of cereal with the largest producer producing 511 quintals of cereals.

As evident from the table, there was relatively little use of cultivated farmland which is typical of smallholders, cereal farming and considerable variations in the amount of inorganic fertilizers, agro-chemicals, and machinery implements and farm-labor use patterns. For such production the farmers cultivated cereal on average of 1.8 ha. The farmers used an average of 342 MDUs of labor, ranging from 3 to 8,334 MDUs; which may reflect the fact that cereal production is labor intensive in Ethiopia. Fertilizer application was minimal with an average of $116.1 \mathrm{~kg}$; while their average expense for agrochemicals and machinery use was 133.9 and 336.27 ETB respectively. The livestock ownership was on average 6.5 TLUs while oxen ownership was around 1.8 meaning almost two oxen per farmer, ranging from no ox to 9 oxen.

To describe some of farm-specific characteristics, as can be observed from tables, male-headed households constituted $76 \%$ of the total sample. Average farmers age was 51 years ranging from 18-103 years while household-size ranged up to $18 \mathrm{members}$, with a mean of six members. Looking at the weather variables in the study area, we find that average annual rainfall was 
$82.1 \mathrm{~mm}$ ranging from $47.5-145.6 \mathrm{~mm}$ while the average temperature was $18.48^{\circ} \mathrm{C}$ ranging from $13.16-23.96^{\circ} \mathrm{C}$. In sum the climate/weather data show a significant declining trend in average rainfall and warming trends in the temperature variable annually during the study period.

Extension participation was represented by extension visits per week/month in which the farmers reported contact with extension agents. Accordingly, about $38 \%$ of the farmers reported contacting with extension agents, seeking agricultural advisory services. Almost half of the sampled farmers had access to credit while $19 \%$ of them obtained remittances from different sources. Femaleheaded households constitute about $24 \%$ of the total sample. About $40 \%$ of the sample farmers adopted soil conserving technologies while $26.6 \%$ of them were involved in water harvesting activities and $19 \%$ of them used irrigation for cropping. Moreover, $19 \%$ of them used irrigation for farming. The educational level of the household head also varied over the years with mean schooling of five years. About $43.44 \%$ of them had attended formal schooling ranging from primary level to tertiary level; out of which $40 \%$ had completed primary level; $7.9 \%$ secondary; and only $1 \%$ had completed tertiary schooling.

\section{ESTIMATION RESULTS AND DISCUSSION}

\section{The SPF parameter estimates}

The estimated parameters of the SPF obtained from simultaneously estimating the TL-functional form and inefficiency models are presented in Tables 3 and 4 respectively. Prior to estimation, we performed Hausman test (Wooldridge, 2002) to see if the unobserved-effects were best treated as fixed or random-effects. The result revealed that the fixed-effect provides a consistent estimation as compared to random-effect. Accordingly, we report fixed-effect estimation, with robust standarderror to diminish the heteroscedasticity problem.

As shown in Table 3, although the parameters from TL function do not have any direct economic interpretation, it is interesting to note that most of the estimated parameters are significantly different from zero at the $5 \%$ or lower significance level. This indicates the fit of the model is very good. Moreover, the estimated parameters could be used in conjunction with the estimated technical inefficiency to estimate additional measures of interest, such as TC, RTS, and TFP growth. Further, the estimated parameters satisfied all production economic theory regularity conditions which require the estimated first-order parameters to be non-negative and less than one, whereas the bordered Hessian matrix of the first and second-order partial derivatives was negative semidefinite and so they are valid at the point of approximation.

The goodness of fit measured either by the $R$-squared or log likelihood function, is satisfactory in the models indicating that the proposed model is a good representation of the data-generation process. Moreover, the parameter $\mathrm{Y}$ associated with variances in SPF, is highly significant, revealing that a great percentage of the disturbance term is due to the presence of technical inefficiency. The results indicate that inefficiency effects did make a significant contribution to the level and variations in cereal production in the study area. Hence, differences in technical efficiency among farms are relevant for explaining output variability in cereal growing farmers. Concerning the other estimated parameters, the majority of coefficients in the SPF are significant at conventional levels. Indeed, some of the interaction and squared terms turned out to be insignificant, due to the nature TL estimation. However, it is widely recognized that in TL, there is high level of multicollinearity due to the interaction and squared term, which causes certain estimated coefficient to be insignificant. Estimates of the trend and its squared term were significantly positive at $1 \%$ level showing that cereal farmers experienced a technical progress with an increasing rate over time.

\section{Technical inefficiency effects}

Empirical finding concerning the sources of efficiency differentials is presented in Table 4. The MLE's results on inefficiency effects show that transient inefficiency was positively and significantly affected by the age, secondary schooling and extreme temperature variations. The age of the farmer, as a proxy of experience and learning-bydoing, is one of the factors enhancing efficiency, while the negative sign of the squared term supports the notion of decreasing returns to experience. Schooling helps farmers to use information efficiently since a better educated farmer acquires more information and is able to produce more from a given input vector. However, inefficiency was negatively and significantly related to the gender, household-size and number of plots. It was negatively and significantly related to remittances, annual average rainfall and average extreme temperature levels. Hence, an increase in these factors, ceteris paribus, led to an increase in efficiency during the period. Similar results were found by Madau (2011) and Bamlaku et al. (2009).

Interpreting the magnitude of the marginal effects of the MLE results, we find that the marginal effect of head's gender on the technical inefficiency was negative, the mean being about 0.06 . Thus inefficiency was reduced by $6 \%$ for a 10-point increase in the household head's gender. Similarly, an increase in the share of household size and number of plots by one percent reduced inefficiency by 0.011 and $0.019 \%$ respectively. On the other hand, a 1 year increase in the age of the household head and secondary educational level, on average, increased inefficiency by 0.015 and $0.095 \%$ respectively. 
Table 3. Parameters from the TL production frontier.

\begin{tabular}{|c|c|c|c|c|c|c|c|c|}
\hline Parameter & Estimate & Rob. SE & Parameter & Estimate & Rob. SE & Parameter & Estimate & Rob. SE \\
\hline$\beta_{0}$ & $5.002^{* * *}$ & 0.419 & $\beta_{F M}$ & -0.002 & 0.004 & $\beta_{W A}$ & 0.002 & 0.018 \\
\hline$\beta_{\mathrm{F}}$ & 0.024 & 0.050 & $\beta_{\mathrm{FW}}$ & $-0.010^{* *}$ & 0.004 & $\beta_{O A}$ & 0.010 & 0.035 \\
\hline$\beta_{P}$ & 0.020 & 0.030 & $\beta_{\mathrm{FO}}$ & $0.016^{* *}$ & 0.009 & $\beta_{\mathrm{tF}}$ & -0.013 & 0.010 \\
\hline$\beta_{\mathrm{L}}$ & $0.369^{* * *}$ & 0.119 & $\beta_{\mathrm{FA}}$ & $0.020^{*}$ & 0.013 & $\beta_{t P}$ & -0.003 & 0.006 \\
\hline$\beta_{M}$ & $0.280^{* * *}$ & 0.065 & $\beta_{P L}$ & 0.001 & 0.005 & $\beta_{\mathrm{tL}}$ & $-0.130^{\star \star *}$ & 0.021 \\
\hline$\beta_{w}$ & 0.057 & 0.070 & $\beta_{P M}$ & $-0.006^{*}$ & 0.003 & $\beta_{\mathrm{tM}}$ & -0.016 & 0.015 \\
\hline$\beta_{0}$ & 0.109 & 0.122 & $\beta_{P W}$ & $0.008^{* *}$ & 0.004 & $\beta_{\mathrm{tw}}$ & 0.002 & 0.013 \\
\hline$\beta_{A}$ & $0.456^{* *}$ & 0.180 & $\beta_{\mathrm{PO}}$ & $-0.020^{* * *}$ & 0.006 & $\beta_{\text {to }}$ & 0.020 & 0.022 \\
\hline$\beta_{F F}$ & -0.002 & 0.010 & $\beta_{P A}$ & 0.001 & 0.009 & $\beta_{\mathrm{tA}}$ & $0.092^{* * *}$ & 0.032 \\
\hline$\beta_{P P}$ & 0.005 & 0.007 & $\beta_{\mathrm{LM}}$ & $0.032^{* * *}$ & 0.008 & $\beta_{t}$ & $0.498^{* \star *}$ & 0.164 \\
\hline$\beta_{\mathrm{LL}}$ & -0.027 & 0.023 & $\beta_{\mathrm{LW}}$ & 0.014 & 0.011 & $\beta_{\mathrm{tt}}$ & $0.418^{\star \star *}$ & 0.053 \\
\hline$\beta_{M M}$ & $0.059^{* * *}$ & 0.013 & $\beta_{\mathrm{LO}}$ & -0.020 & 0.020 & $\mathrm{~B}^{2}$ & Within & 0.761 \\
\hline$\beta_{w w}$ & $0.025^{* *}$ & 0.010 & $\beta_{\llcorner A}$ & -0.045 & 0.029 & $\mathrm{R}^{2}$ & Overall & 0.704 \\
\hline$\beta_{\circ \circ}$ & $0.084^{* *}$ & 0.046 & $\beta_{M W}$ & 0.002 & 0.006 & & $\sigma_{u}$ & 0.613 \\
\hline$\beta_{\mathrm{AA}}$ & -0.066 & 0.069 & $\beta_{\mathrm{MO}}$ & -0.004 & 0.011 & & $\sigma_{v}$ & 0.744 \\
\hline$\beta_{\mathrm{FP}}$ & 0.001 & 0.002 & $\beta_{\mathrm{MA}}$ & -0.009 & 0.016 & & Y & 0.406 \\
\hline$\beta_{\mathrm{FL}}$ & 0.006 & 0.008 & $\beta_{w o}$ & -0.012 & 0.013 & & & \\
\hline
\end{tabular}

${ }^{*} \mathrm{P}<0.05,{ }^{* *} \mathrm{P}<0.01$ and ${ }^{* * *} \mathrm{P}<0.001$. Subscripts on $\beta$ coefficients refer to inputs: $\mathrm{F}=$ Fertilizers; $\quad \mathrm{P}=$ Agrochemicals; $\mathrm{L}=\mathrm{Labor} ; \mathrm{M}=\mathrm{Machinery}$; $\mathrm{W}=$ Livestock; $\mathrm{O}=$ Number of oxen; $\mathrm{A}=$ Farm-area.

Table 4. Technical inefficiency effects result.

\begin{tabular}{llllllll}
\hline Variable & Coef. & SE & MEs & Variable & Coef. & SE & MEs \\
\hline Farm-specific factors & & & & & & & \\
Head's-gender & $-0.314^{*}$ & 0.18 & -0.061 & Secondary-schooling & $0.485^{*}$ & 0.282 & 0.095 \\
Head's-age & $0.075^{* *}$ & 0.031 & 0.015 & Tertiary-schooling & 0.396 & 0.7 & 0.077 \\
Age sq. & $-0.061^{* *}$ & 0.029 & -0.012 & Credit-access & 0.056 & 0.149 & 0.011 \\
Household-size & $-0.052^{*}$ & 0.033 & -0.010 & If any ox & -0.234 & 0.181 & -0.046 \\
Primary-schooling & -0.006 & 0.162 & -0.001 & Remitances & $-0.387^{*}$ & 0.222 & -0.075 \\
& & & & & & & \\
Adoption technologies & & & & & & & \\
Number of plots & $-0.097^{*}$ & 0.054 & -0.019 & Irrigation & -0.213 & 0.219 & -0.042 \\
Soil-conservation & -0.205 & 0.166 & -0.04 & Off/non-farm & 0.113 & 0.165 & 0.022 \\
Water-harvesting & -0.273 & 0.189 & -0.053 & Ext. services & -0.237 & 0.159 & -0.046 \\
& & & & & & & \\
Weather factors & & & & & & & \\
PRECIP & $-0.076^{* *}$ & 0.03 & -0.015 & Rainfall variation & -59.151 & 67.514 & -11.54 \\
AMT & $-1.806^{* *}$ & 0.843 & -0.352 & Temp. variation & $0.323^{\star * *}$ & 0.113 & 0.063 \\
Constant & $-1.29^{\star * *}$ & 0.068 & & Log LH & -1512.15 & & \\
\hline
\end{tabular}

${ }^{*}: p<0.05 ;{ }^{* *}: p<0.01 ;{ }^{* * *}: p<0.001$.

\section{Technical efficiency scores}

Estimates of technical efficiency scores in the form of percentage distributions are reported in Table 5. The persistent technical efficiency component is found to be about $80 \%$, on average with a less dispersion. On the other hand, the transient technical efficiency component is found to be quite low, scoring mean of $71 \%$. This variability between persistent and transient efficiency scores which is in line with the findings of Kumbhakar et al. (2014) and Filippini and Greene (2016) clearly demonstrates the existence of significant farmheterogeneity in the sample and should be considered in efficiency modeling and specifications. As the combination 
Table 5. Distribution of technical efficiency scores.

\begin{tabular}{lcccc}
\hline Parameter & Mean & Std. Dev. & Min & Max \\
\hline Transient Technical Efficiency & 0.71 & 0.12 & 0.05 & 0.93 \\
Persistent Technical Efficiency & 0.80 & 0.05 & 0.56 & 0.92 \\
Overall Technical Efficiency & 0.57 & 0.10 & 0.03 & 0.80 \\
\hline
\end{tabular}

Source: Author's computation.

of the two efficiency components, estimate of the overall technical efficiency shows a mean score of $57 \%$ during the period, whilst most farms in the sample (65 to 81\%) have achieved technical efficiency scores greater than $75 \%$.

The overall implication of these results for overall or each year is that the cereal farmers were technically less efficient. Since technical efficiencies scores were calculated as an output-oriented measure, results indicate that there was room for improvement, and output could have increased substantially if inefficiency was eliminated. Meaning that, the farmers could be able to increase their output by about $43 \%$ using their resources more effectively. Expressing in other way, a $43 \%$ increase in total output could have been achieved during this period by decreasing proportionally the quantity of inputs used without altering the total volume of production.

\section{Output and TFP growth decomposition results}

The decomposed components of output growth and TFP changes of the cereal farmers over the period of 19992015 are presented in Table 6, where the first two columns are based on Equation 9 and the last two on Equation 10. In each case, the average annual rate change during the period under consideration is reported first, followed by the relative contribution of each effect to the observed output growth and TFP changes. TFP is then decomposed into its three main components, namely, TC component which is dominated by the time trend effect, the TECs and the SE components. The first two components further decomposed into several subcomponents such as contributions from different technology shifters. In particular, the TC effect has decomposed into sub-components such as neutral and biased components. The TECs has decomposed into sub-components such as contributions from autonomous change; change due to inputs; change due to farmer/farm-specific characteristics and change due to environmental factors.

From Table 6 it is clear that Equations 9 and 10 yield different results regarding the sources of output growth. This is to be expected, as the hypothesis of constant RTS has been rejected and the computation of the SE and the TEC effects has been performed differently. As evidence of increasing RTS has been found, the relative contribution of TFP to output growth is underestimated when Equation 10 is employed, whereas the opposite is true for the SE, as long as the TECs and the SEs are measured in the same way. In this case, part of output growth would be falsely attributed to TFP changes whereas it is in fact associated with increases in input use. However, this is not reflected in the results when different measures of both the TECs and the SEs have been used. Besides these differences, it should be noticed that the portion of unexplained residual is greater when the decomposition of output growth is based on Equation 10.

Given the rejected hypotheses of constant RTS and neutral production frontier, we precede the decomposition analysis of output growth and interpretations based on Equation 9. As can be seen from Table 6 during the period, average annual output growth was 1.29. A greater share of the observed output growth $(71.13 \%)$ was due to the TFP growth and a smaller share $(22.3 \%)$ to SE. Specifically, $0.29 \%$ of the observed output growth is attributed to the aggregate input growth mainly associated with farm-size and labor growth while the rest percentage of the output growth was attributed to the TFP changes. TC was found to be the most important source of TFP changes and thus to the output growth having a positive estimate. In particular, an average annual rate of TC is estimated at an average growth rate of 1.16 that accounts for $89.76 \%$ of the observed output growth. This rate of TC is indicating the cereal farming was technically progressed. Regarding the sources of TC, it can be seen from Table 6 that $1.82 \%$ was due to the neutral component and only $0.66 \%$ reduction was due to the biased component. The result is in accordance with previous empirical findings reported that TC is the main source of TFP growth (Karagiannis and Tzouvelekas, 2005; Alexander et al., 2015).

The empirical result also exhibits the SE has affected positively the TFP growth that compromises with the exhibited increasing RTS and aggregate increase in input usage results reported over time. However, the relative contribution of SE was small compared to that of TC. During the period 1999-2015, SE has contributed to the annual TFP growth by an average rate of $2.57 \%$. This indicates that, the SE component and thus its effect is a significant figure that would have been ignored if constant RTS were falsely assumed. In such a case, TFP growth 
Table 6. Decomposition of output growth and TFP changes.

\begin{tabular}{lcccc}
\hline \multirow{2}{*}{ Decomposition } & \multicolumn{2}{c}{ Based on Equation 9 } & \multicolumn{2}{c}{ Based on Equation 10 } \\
\cline { 2 - 5 } & Mean & Percentage & Mean & Percentage \\
\hline Output growth & 1.29 & 100 & 1.29 & 100 \\
Size effect & 0.29 & 22.30 & 0.25 & 19.36 \\
Fertilizers & 0.01 & 0.57 & 0.01 & 0.60 \\
Agrochemicals & 0.01 & 0.78 & 0.02 & 1.90 \\
Labor & 0.04 & 2.82 & 0.05 & 3.64 \\
Machinery & 0.01 & 0.78 & 0.004 & 0.28 \\
Livestock & 0.05 & 4.08 & 0.03 & 2.55 \\
Oxen & 0.05 & 3.52 & 0.04 & 3.49 \\
Farm-area & 0.13 & 9.75 & 0.09 & 6.89 \\
Total Factor Productivity (TFP) Changes & 1.003 & 71.13 & 1.12 & 86.67 \\
Technical Changes (TCs) & 1.16 & 89.76 & 1.16 & 89.76 \\
Neutral & 1.82 & 140.94 & 1.82 & 140.94 \\
Biased & -0.66 & -51.18 & -0.66 & -51.18 \\
Scale Effect (SE) & 0.028 & 2.57 & - & - \\
Technical Efficiency Changes (TECs) & -0.18 & -15.12 & -0.04 & -3.09 \\
Change due to passage of time & -0.04 & -3.09 & & \\
Change due to inputs & 0.001 & 0.81 & & \\
Change due to environmental factors & -0.15 & -11.40 & & \\
Changes due to farm-characteristics & 0.002 & 0.17 & & \\
Unexplained Residuals & 0.073 & 5.650 & 0.078 & 6.029 \\
\hline
\end{tabular}

Source: Author's computation.

would have been overestimated. Specifically, the estimated average annual rate of TFP growth would have been $86.67 \%$ instead of $71.13 \%$. Consequently, the results demonstrate that, there would have been significant differences in TFP growth by not accounting simultaneously for the SE. Furthermore, not accounting for the SE can lead not only to errors but also to misconceptions concerning the potential sources of TFP and output growth, as noticed in similar studies (Karagiannis and Tzouvelekas, 2005).

On the other hand, the TECs have affected negatively both TFP changes and hence the output growth. Its effect is unconstructive, as the pattern of changes in technical efficiency indicated movements contrary to the production frontier over time. Hence, the empirical result exhibits the TEC was the main source for the reduction of TFP and output growth. In particular, it evinces an average reduction of 0.18 in TFP growth and hence a decline in $15.12 \%$ of the observed growth was attributed to changes in TEC or changes in its components during the period 1999-2015. This result (the negative effect of TECs), is in line with the results from technical efficiency scores, as evidenced in Table 6 that technical efficiency estimates has dropped between 1999 and 2015 years. Moreover, to get more insights into the sources of TECs that contributed in reduction of TFP, we turn our attention to the components of TECs from Equation 9 to draw some analysis.

Specifically, the empirical result indicates that changes due to environmental factors were the most significant determinants as a main cause for deteriorating TECs; meanwhile only a small portion of this decline was due to pure autonomous changes. On the other hand, it is found that the changes due to the inputs factors and due to farm-characteristics were essential in minimizing the worst effect of TECs on the TFP growth, by positively contributing to the TECs. Meanwhile it is important to notice that the effect of the inputs factor on TEC over time has similar result as that of the size effect on the output growth. That is, a change due to the inputs factor improves the performance (increased TECs) similar to the positive effect of aggregate input use on the output growth. In general from the components of TECs; change due to inputs and changes due to farm-characteristics were the most important, both cancelling the negative impact of the environmental factors. Hence the empirical findings reveal that TFP changes and thus the output growth was largely due to adoption of improved technologies and scale effect rather than improvement in technical efficiency of the smallholders. It demonstrates that TFP has been increasing, driven primarily, by positive TC, changes due to SE and changes due to inputs.

\section{CONCLUSION AND POLICY IMPLICATIONS}

This paper provides a parametric decomposition of output 
growth and TFP changes extends production approach to the case of non-neutral stochastic frontier. The analysis is based on five-point unbalanced panel dataset from Ethiopian smallholder cereal farmers observed for the period of 1999-2015. The paper used recently developed SPF panel data model that decomposes technical efficiency into components and extends the model to include the output growth and TFP growth decompositions. Output growth was decomposed into two of its sources - factor accumulation and TFP changes, and each was further decomposed into components. Input growth itself was decomposed into individual inputs contribution while TFP growth was intern decomposed into rate of TC, SE and TEC components. Further TEC was also decomposed into components such as - autonomous changes, changes in inputs use, changes in the farm-specific characteristics and changes in weather/environmental factors.

Efficiency estimation results show that the potential for improving the production efficiency of cereal farmers is immense, as some farmers are operating at as low as $45 \%$ level of efficiency. Input elasticities were significantly positive and hence show an increase in the use of each input has contributed to enhance cereal production. Results from growth decomposition models evinced that a greater share of the observed output growth was due to the TFP changes compared to that of input growth. Specifically, aggregate input use increased at annual mean rate of $29(22.3 \%)$ while the rest percentage was attributed to that of TFP changes. The findings further indicate TFP changes have been increased mainly driven by TCs, while SE contributed significantly over the period. This indicates that, there would have been significant differences in TFP growth by not accounting simultaneously for the SE.

On the other hand, TECs was found to affect negatively the rate of TFP changes and hence on the output growth, though its effect was very little. Consequently, TEC was found to be the main source for the reduction of TFP changes and output growth. In particular, during the period 1999-2015 significant reductions in both TFP changes were attributed to the depressing changes in TEC streamed from changes in its components. In this regard the empirical results indicate that changes due to passage of time and due to environmental factors were found to affect negatively the rate of TFP while changes due to inputs and due to farm-characteristics were positive. Hence the effects of change due to inputs use and change due to farm-characteristics on TEC, is in line with that of size effect we found on the output growth over the period. In sum from the components of TECs, change due to inputs and changes due to farmcharacteristics were the most important, both cancelling the negative impact of the environmental factors. It should be noticed that change due to inputs was far more important in explaining changes in technical efficiency contributing $0.81 \%$, in contrast to their explanatory role for the size effect.

In sum, the analysis undertaken in this paper demonstrated that the output growth was largely due to change arising from two components - the TFP change and the input growth over time. On the other hand, the TFP growth showed that TC and SE are the two most important determinants of TFP growth over the period. This demonstrates TFP has been increasing, driven primarily by change due to TC, and due to changes in $\mathrm{SE}$, and also due to changes inputs and changes due to farm-characteristics. In connection to these, though the average level of technical efficiency of the cereal farmers is as high as $57 \%$, yet the result suggests that technical efficiency does not play significant role on TFP changes and output growth as the technical efficiency did not improve overtime which might be attributable to TEC effect. This implies that TFP growth and thus the output growth was largely due to adoption of improved technologies and SE rather than improvement in technical efficiency of the smallholders.

An important implication of these results is that the rate of TFP changes hence the output growth in cereal crops is mainly driven by technological progress, suggesting that policies aiming at enhancing the adoption of technological innovations and at increasing investments in agricultural extension services are significantly effective. Specifically, the increase of TFP in Ethiopian cereal production requires policies aiming at improving technological change, taking into account the farmer's know-how, could be intensified to improve cereal farm productivity growth significantly. For instance public investment in agricultural extension service and technological innovations, such as escalating adoptions strategies, could be intensified to improve cereal farm productivity growth and output growth. Therefore, government policies directed toward enhancing investment for agricultural extension service that improves technological progress and enables farmers to benefit from optimal input operations and farms best practice should form an essential part of the recommendations drawn from the study.

\section{CONFLICT OF INTERESTS}

The authors have not declared any conflict of interests.

\section{REFERENCES}

African Development Bank (AfDB) (2018). Federal democratic republic of Ethiopia: Country strategy paper-CSP, 2016-20.

Alexander BD, Stavroula M, Kien CT (2015). Sources and measurement of agricultural productivity and efficiency in Canadian provinces. Canadian Journal of Agricultural Economics pp. 1-22.

Baltagi BH (2008). Econometric analysis of panel data (4th ed.). Chichester: John Wiley \& Sons.

Bamlaku BA, Nuppenau EA, Boland H (2009). Technical Efficiency of Farming Systems across Agro Ecological Zones in Ethiopia: An Application of Stochastic Frontier Approach. Agricultural Journal 4(4): 
202-207.

Barnwal P, Kotani K (2013). Climatic impacts across agricultural crop yield distributions: An application of quartile regression on rice crops in Andhra Pradesh, India. Ecological Economics 87:95-109.

Battese GE, Coelli TJ (1988). Prediction of firm-level technical efficiencies with a generalized frontier production function and panel data. Journal of Econometrics 38(3):387-399.

Battese GE, Coelli TJ (1992). Frontier production functions, technical efficiency and panel data: With application to paddy farmers in India. Journal of Productivity Analysis 3:153-169.

Beyan A, Jema H, Endrias G (2013). Analysis of farm households' technical efficiency in production of smallholder farmers: The case of Girawa district, Ethiopia. Journal of Agricultural and Environmental Science 13(12):1615-621.

Farrell MJ (1957). Measurement of productive efficiency. Journal of the Royal Statistical Society 120(3):253-281.

Filippini M, Greene WH (2016). Persistent and transient productive inefficiency: A maximum simulated likelihood approach. Journal of Productivity Analysis 45(2):187-196.

Gebreegziabher Z, Mekonnen A, Deribe R, Abera S, Kassahun MM (2013). Crop-livestock inter-linkages and climate change implications for Ethiopia's agriculture: A Ricardian approach, EfD Discussion paper, 13-14.

Greene W (2005a). Reconsidering heterogeneity in panel data estimators of the stochastic frontier models. Journal of Econometrics 126(2):269-303.

Greene W (2005b). Fixed and random effects in stochastic frontier models. Journal of Productivity Analysis 23:7-32.

Harris I, Jones P, Osborn T, Lister D (2014). Updated high-resolution grids of monthly climatic observations-The CRU TS3, 10 dataset. International Journal of Climatology 34(3):623-642.

Huang C, Liu J (1994). Estimation of a non-neutral stochastic frontier production function. Journal of Productivity Analysis 5:171-180.

Jondrow J, Lovell C, Materov I, Schmidt P (1982). On the estimation of technical inefficiency in stochastic frontier production model. Journal of Econometrics 19:233-238.

Karagiannis G, Tzouvelekas V (2001). Self dual stochastic production frontiers and decomposition of output growth: The case of olivegrowing farms in Greece. Agricultural and Resource Economic Reviews 30:168-178.

Karagiannis G, Tzouvelekas V (2005). Explaining output growth with a heteroscedastic non-neutral production frontier: The case of sheep farms in Greece, European Review of Agricultural Economics 32(1):51-74.

Kumbhakar SC (1990). Production frontiers, panel data, and time varying technical inefficiency. Journal of Econometrics 46:201-212.

Kumbhakar SC, Heshmati A (1995). Efficiency measurement in Swedish dairy farms: An application of rotating panel data. American Journal of Agricultural Economics 77:660-674.

Kumbhakar SC (2000). Estimation and decomposition of productivity change when production is not efficient: A panel data approach. Econometric Reviews 19:425-460.

Kumbhakar SC, Lien G, Hardaker J (2014). Technical efficiency in competing panel data models: A study of Norwegian grain farming. Journal of Productivity Analysis 41(2):321-337.
Kumbhakar SC, Wang HJ, Horncastle AP (2015). A practitioner's guide to stochastic frontier analysis using stata. NY: Cambridge University Press.

Madau A (2011). Parametric Estimation of Technical and Scale Efficiencies in Italian Citrus Farming. Agricultural Economics Review 12(1):91-112.

Schmidt P, Sickles R (1984). Production frontier and panel data. Journal of Business and Economic Statistics 2(4):367-374.

The World Bank (2017). WB in Ethiopia: Country's economic overview. Washington, DC.

Wang H, Schmidt P (2002). One-step and two-step estimation of the effects of exogenous variables on technical efficiency levels. Journal of Productivity Analysis 18:129-144.

Wooldridge JM (2002). Econometric analysis of cross-section and panel data. Cambridge, Massachusetts: The MIT Press.

Yohannes H (2016). A review on relationship between climate change and agriculture. Journal of Earth Science and Climatic Change 7(2):335. 